(C) 2016 IEEE. Personal use of this material is permitted. Permission from IEEE must be obtained for all other uses, in any current or future media, including reprinting/republishing this material for advertising or promotional purposes, creating new collective works, for resale or redistribution to servers or lists, or reuse of any copyrighted component of this work in other works. 


\title{
A Novel Superconducting Magnet Excited Linear Generator for Wave Energy Conversion System
}

\author{
Omar Farrok, Md. Rabiul Islam, Member, IEEE, M. Rafiqul Islam Sheikh, Youguang Guo, Senior Member, IEEE, \\ Jianguo Zhu, Senior Member, IEEE, and Wei Xu, Senior Member, IEEE
}

\begin{abstract}
In almost every permanent magnet linear generator (PMLG), demagnetization would greatly degrade the electricity generation capability over time. This paper proposes a novel electromagnetic linear generator (EMLG) for direct drive power generation from oceanic wave which consists of superconducting magnets instead of conventional permanent magnets to create sufficiently strong magnetic field to produce electricity. The proposed generator can avoid the demagnetization problem of the conventional PMLG. To verify the feasibility of the new concept, a generator is designed. Yttrium barium copper oxide is used to make the superconducting magnet. The finite element analysis is performed by using the commercial software package ANSYS/ANSOFT to analyze the performance of the proposed EMLG, and the genetic algorithm has been used to find the optimal pole size, pole pitch, air gap length and load variation to maximize the output power. Magnetic pole shoes are designed in such way that they can effectively minimize force ripples and cogging force. The results are analyzed and discussed. The results demonstrate that the proposed generator almost eliminates the demagnetization problem of the conventional PMLG with some other built in advantages. It is found that the proposed generator is up to $96 \%$ efficient. The results demonstrate excellent feature of the proposed generator.
\end{abstract}

Index Terms - Direct drive, EMLG, superconducting magnet, wave energy converter.

\section{INTRODUCTION}

B ECAUSE OF the global energy crises, scientists and engineers are working hard to overcome the problem by utilizing renewable energy sources (RESs) [1], [2]. The ocean is a gigantic renewable energy source which covers around three quarters of the earth's surface and the energy can be extracted from the waves of the ocean in many ways [3]. Oceanic wave has high power density compared to solar or wind energy and it is available, predictable and environment friendly [4]. Electricity generated from RES fluctuates at most of the time, depending upon the environmental conditions, which vary on the time scales from seconds to days. Therefore, there are significant challenges to manage the

Manuscript received December 30, 2015.

O. Farrok, M. R. Islam, and M. R. I. Sheikh are with Department of Electrical and Electronic Engineering, RUET, Rajshahi 6204, Bangladesh. Phone and fax: 0721 750356, e-mail: omarruet@gmail.com, rabiulbd@hotmail.com.

Y. G. Guo and J. G. Zhu are with the Faculty of Engineering and Information Technology, University of Technology Sydney, Broadway, NSW 2007, Australia. e-mail: $\quad$ youguang.guo-1@uts.edu.au, jianguo.zhu@uts.edu.au.

$\mathrm{W} . \mathrm{Xu}$, is with the College of Electrical and Electronic Engineering, HUST, Wuhan 430074, China, e-mail: weixu@ hust.edu.cn. stability, security and reliability for power grids while smoothing the generated power and thus making the best use of RES [5]. At present, the major linear generators (LGs) used for wave energy conversion (WEC) are constructed with permanent magnets (PMs) to produce magnetic flux, which usually have PMs on the translator and usually are linear synchronous generators (LSGs) and more specifically permanent magnet linear generators (PMLGs) [6], [7]. The conventional LGs have the disadvantages of complex translator structure and unexpected translator temperature rise, which might cause irreversible demagnetization of PMs and mechanical damage [8]. Fig. 1 shows the basic block diagram of a wave energy converter from oceanic wave energy to power grid, where the dashed rectangle represents the status of the nature of power at different steps of WEC.

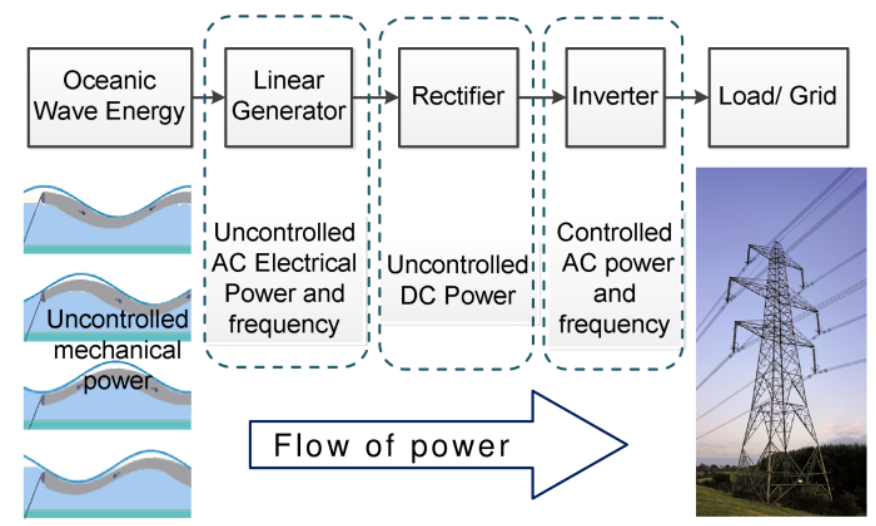

Fig. 1. Power flow diagram of the wave energy converter.

The design of a prototype linear synchronous motor driving system using high temperature superconductor (HTS) to make superconducting magnet (SM) for magnetic levitation transportation was presented in [9], [10]. A single sided HTS linear synchronous motor with an HTS bulk magnet array as its secondary has been developed, and the electromagnetic parameters of this motor have been calculated to verify the performance [11]. Two types of HTS LSG have been analyzed in [12] which modeled an HTS bulk magnet array or an HTS tape coil as their secondary mover. This work shows the development and tests of a linear HTS motor as the starting point to the design and construction of a high power HTS synchronous machine [13].

Basically all PMs are hard magnetic materials which are usually characterized by a wide hysteresis loop of $B-H$ with four quadrants. In fact, while these PMs are performing their operation in LGs to produce electricity, the $B-H$ curves are operated in the second quadrant as illustrated in Fig. 2. 
Therefore, the basis for the calculation of a PM is the portion of its hysteresis loop located in the second quadrant, known as the demagnetization curve.

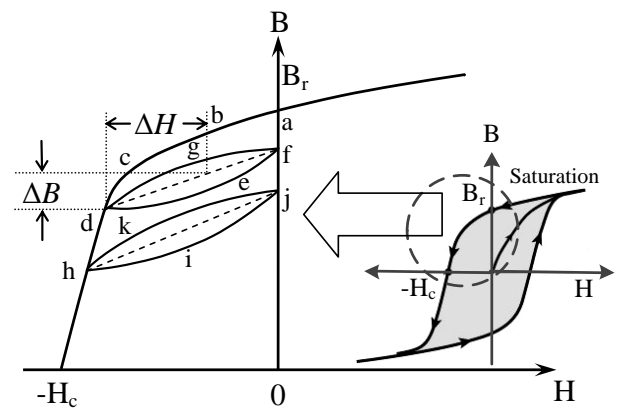

Fig. 2. Demagnetization curve of a permanent magnet.

Consider a new PM that was not been used in any operation, where $B_{r}$ is the magnetic remanence or remanent magnetism and $H_{c}$ is the coercive force. Before starting generator operation the magnetic flux density, $B$ is located at point $a$. When electricity is generated in the armature coil for the first time, due to the induced armature current a reverse magnetic field is created according to the Lenz's law. The induced emf/phase $E_{p}$ can be determined by (1), where $\Phi_{g}$ is the air gap flux which can be expressed as (2).

$$
\begin{gathered}
E_{p}=\pi \sqrt{2} f N_{1} k_{w l} \varphi_{g} \\
\varphi_{g}=\varphi_{f}-\varphi_{a}-\varphi_{l}
\end{gathered}
$$

where $\Phi_{f}, \Phi_{a}$ and $\Phi_{l}$ are the excitation flux, armature reaction flux and leakage flux, respectively. $k_{w l}$ is known as winding factor. At no load condition, $\Phi_{g} \approx \Phi_{f}$ as $\Phi_{l}$ is very small. Therefore, when the generator supplies electrical power to the load, due to armature reaction, $\Phi_{a}$ mainly opposes the excitation flux. This reverse magnetic field is applied to the previously magnetized PM, and therefore, the magnetic flux density drops down from point $a$ to the magnitude determined by the point $d$ followed by the abcd line. When the PMLG is not running, that is, when it does not produce electricity at that moment when the reverse magnetic field does not exist, the flux density returns to the point $f$ instead of point $a$ followed by the def line according to a minor hysteresis loop. Thus, the application of a reverse field has reduced the remanence. Reapplying an opposite magnetic field intensity will again reduce the flux density, completing the minor hysteresis loop defgd by returning the core to approximately the same value of flux density at the point $d$ as before. The minor hysteresis loop may usually be replaced by a straight line $d f$ for simplification called the recoil line. This line has a slope called the recoil permeability $\mu_{\text {rec }}$. As long as the negative value of applied magnetic field intensity does not exceed the maximum value corresponding to the point $d$, the PM may be regarded as reasonably permanent. However, if a greater negative field intensity $H$ is applied, the magnetic flux density will be reduced to a value, say, point $h$ lower than that at point $d$. As the magnitude of reverse magnetic field depends on the velocity of the LG for a particular load which varies with wave motion, therefore $B$ will be reduced to a new value. On the removal of $H$, a new and lower recoil line $h j$ will be established and again a secondary hysteresis loop hijkh will be formed and will never return to the previous minor hysteresis loop defgd because there is no way in the PMLG to give sufficiently high magnetic field intensity in the positive $H$ direction so that it can re-gain remanent magnetism $B_{r}$.

Most of the conventional PMLG has the drawback of demagnetization problem and has fixed flux, therefore there is no way to control the voltage or power with randomly changeable wave motion [14]-[17]. This paper proposes a novel EMLG for direct drive power generation from oceanic wave which consists of SMs instead of conventional permanent magnets to create strong magnetic field excitation to produce electricity. The second generation HTS Yttrium Barium Copper Oxide (YBCO) is used to make the SM as it is an advanced conductor with a high irreversibility field and critical current density in an external magnetic field. They can operate either with liquid nitrogen or commercial cryocoolers, thereby eliminating the requirement of expensive liquid helium. The proposed electromagnetic LG (EMLG) consisting of SM has eliminated these problems and can be readily capable of regulating the output power by controlling the field excitation.

\section{THE PROPOSED GENERATOR}

\section{A. Winding Configuration}

The proposed LG is constructed with some individual units in which there are twenty coils named $C_{1}, C_{2} \ldots C_{20}$ and ten windings named $W_{l}, W_{2} \ldots W_{l o}$. Each of the winding consists of a pair of coils with $180^{\circ}$ phase shifted to each other, where one coil is wounded in clockwise direction and the other coil is wounded in counterclockwise direction. Each winding has a particular phase shift for even distribution of electrical power and also reducing the cogging force. The winding configuration is illustrated in Fig. 3.

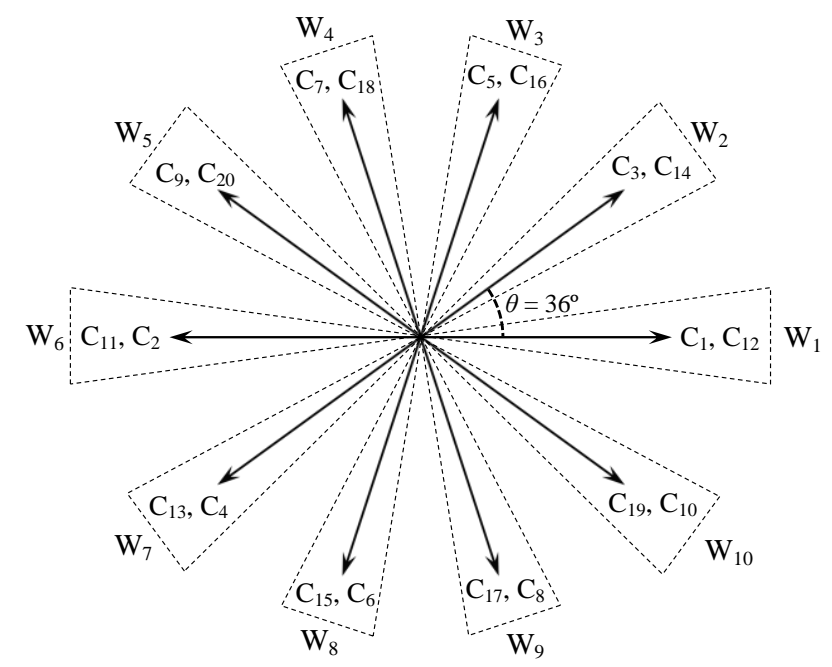

Fig. 3. Winding vector diagram.

\section{B. Construction}

The proposed generator is constructed with a translator in the middle position which moves upward and downward as 
shown by an arrow and some SMs are located at both sides of the translator. Unlike other LGs the armature winding is placed in the translator and field excitation is placed in the stator. Fig. 4 shows the construction, flux density and dimensions of the proposed EMLG.

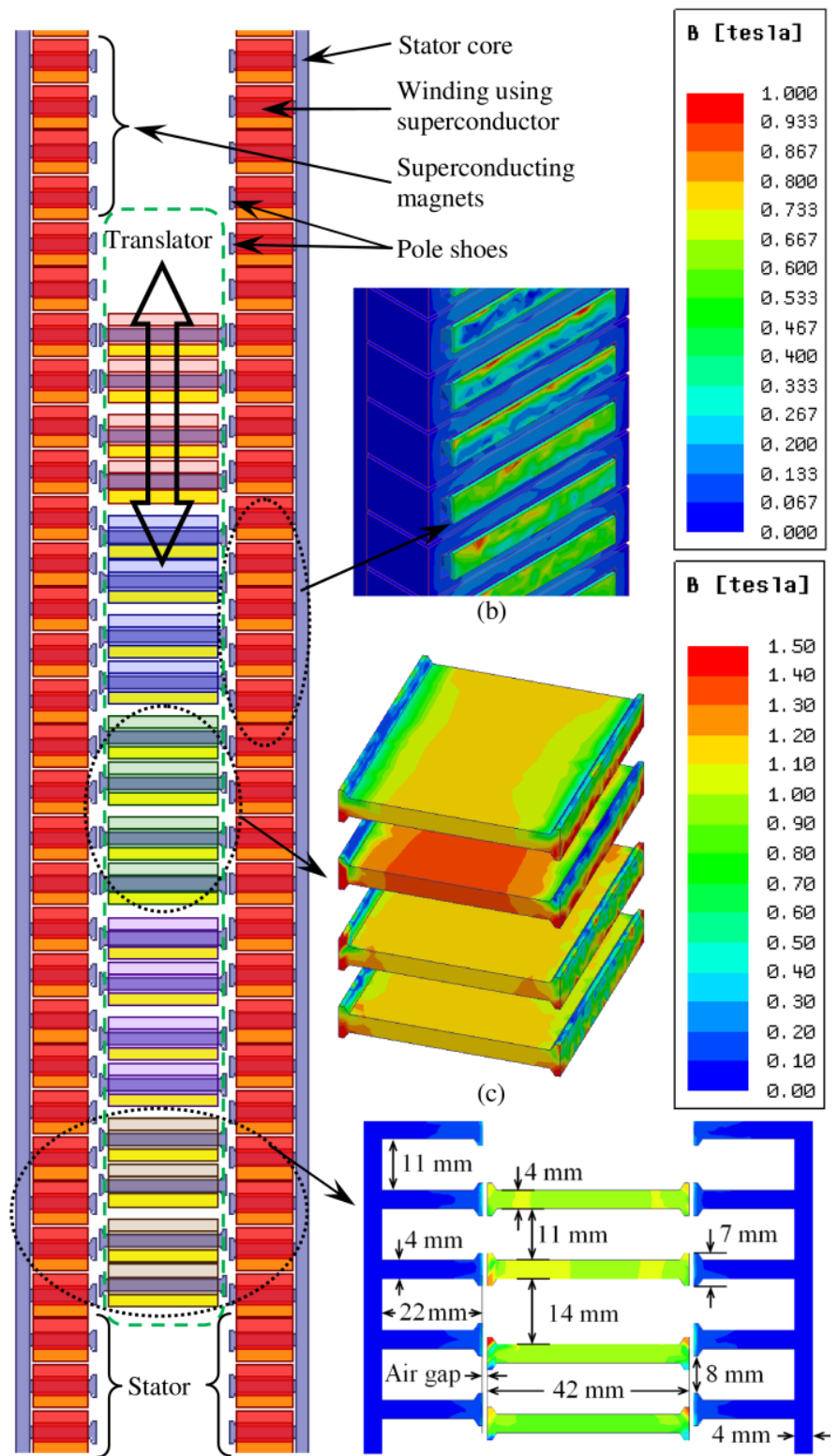

(a)

(d)

Fig. 4. Design of the proposed EMLG: (a) the front view, (b) flux density of stator core, (c) translator core, and (d) dimensions.

\section{Equivalent circuit diagram}

Fig. 5 shows the equivalent circuit diagram of the proposed EMLG. The winding configuration of is such that $W_{n}$ and $W_{n+5}$ generate the same magnitude of voltages but opposite polarity. These two windings are configured in series to increase voltage and the armature resistances of both windings are summarized as $R_{a}$ to simplify. Individual bridge rectifiers are used to convert the generated ac power into dc power to the load. The excitation is obtained from SM array as shown in Fig. 4.

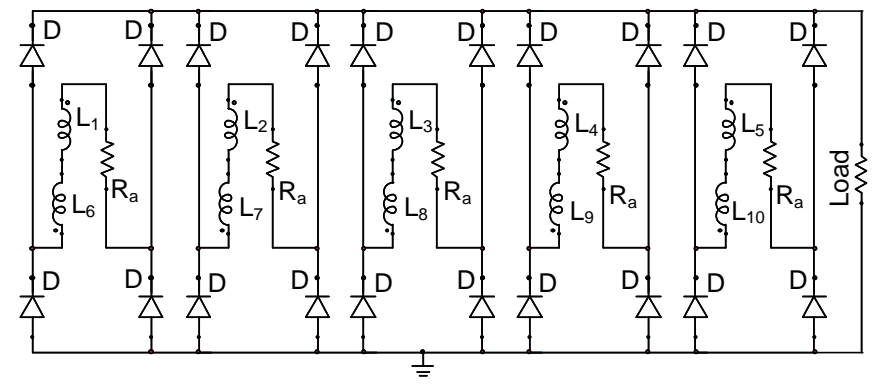

Fig. 5. Equivalent circuit diagram.

\section{Some parameters}

The proposed EMLG is basically a linear synchronous generator. The frequency, $f$ of this generator can be found from (3)

$$
f=\frac{V_{l}}{2 \tau}
$$

where, $V_{l}$ is the linear velocity of the generator and $\tau$ is the pole pitch. The form factor, $k_{f}$ of the excitation field is defined as

$$
k_{f}=\frac{B_{m g_{1}}}{B_{m g}}=\frac{4}{\pi} \sin \frac{\alpha_{i} \pi}{2}
$$

where $B_{m g l}$ is the amplitude of the fundamental component of the air gap magnetic flux density, $B_{m g}$ the maximum value of the air gap magnetic flux density and $\alpha_{i}$ is the pole shoe to pole pitch ratio. The fundamental $\Phi_{f 1}$ without armature reaction can be determined by (5).

$$
\varphi_{f_{1}}=L_{i} \int_{0}^{\tau} B_{m g_{1}} \sin \left(\frac{\pi}{\tau} x\right) d x=\frac{2}{\pi} \tau L_{i} B_{m g_{1}}
$$

Some significant parameters of a single unit of the proposed LG are given in Table I.

TABLE I

SELECTED PARAMETERS

\begin{tabular}{|l|c|c|}
\hline \multicolumn{1}{|c|}{ Name of Item } & Dimension & Unit \\
\hline Translator tooth width & 7 & $\mathrm{~mm}$ \\
\hline Translator slot width & 8 & $\mathrm{~mm}$ \\
\hline Translator width & 44 & $\mathrm{~mm}$ \\
\hline Translator tooth pitch $(\tau)$ & 15 & $\mathrm{~mm}$ \\
\hline Stroke length & 100 & $\mathrm{~mm}$ \\
\hline No. of turns in the copper coil & 200 & turns \\
\hline Thickness of core & 4 & $\mathrm{~mm}$ \\
\hline Pole shoe to pole pitch ratio $\left(\alpha_{i}\right)$ & 0.467 & \\
\hline Stator width & 26 & $\mathrm{~mm}$ \\
\hline Depth of a single unit of the generator & 50 & $\mathrm{~mm}$ \\
\hline Velocity of translator $\left(V_{l}\right)$ & $1 \sim 2$ & $\mathrm{~m} / \mathrm{s}$ \\
\hline Air gap length & $1 \sim 2$ & $\mathrm{~mm}$ \\
\hline Maximum efficiency & $96 \%$ & \\
\hline Peak dc voltage & 27 & $\mathrm{~V}$ \\
\hline Core loss & $0.1 \sim 0.5$ & $\mathrm{~W}$ \\
\hline Load resistance & $1 \sim 10$ & $\Omega$ \\
\hline
\end{tabular}

\section{Simulation RESUlts}

The coordinate system of this design is 3D Cartesian and the applied force direction is along the $\mathrm{z}$ axis which practically works in the upward/downward direction. In this simulation, the default value for translator velocity is $1 \mathrm{~m} / \mathrm{s}$, air gap is 1 
$\mathrm{mm}$ and a $3 \mathrm{ohm}$ resistance is considered as the default load. The applied force denoted by Force_z and force components along $\mathrm{x}$ axis and $\mathrm{y}$ axis that are denoted by Force_ $\mathrm{x}$ and Force_y, respectively are shown in Fig. 6.

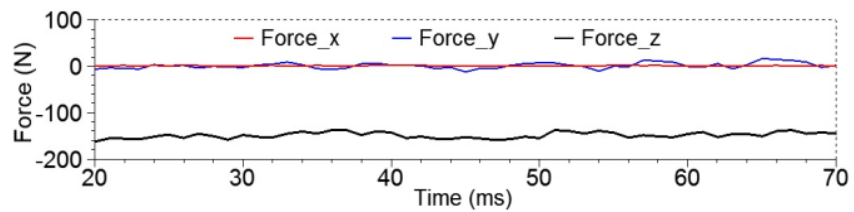

Fig. 6. Applied force and force components.

The generator is such designed that force components, Force_x and Force_y are very low, otherwise they would affect the bearings and related moving accessories and would shorten their service life. The generated voltage, current and power for default velocity, air gap and load condition are shown in Fig. 7.

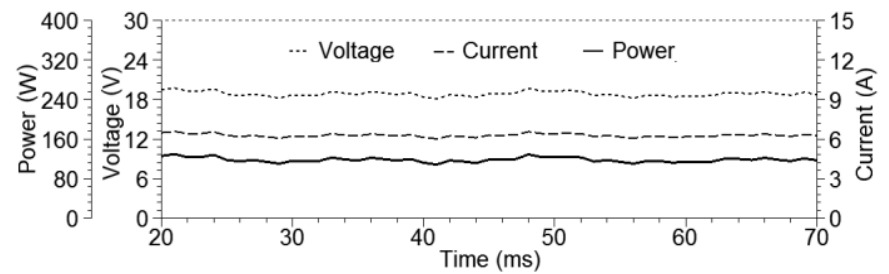

Fig. 7. Generated voltage, current and power at the default condition.

The induced voltage and currents of coil $C_{l}$ for different air gaps are shown in Fig. 8. It is seen that when the air gap is increased, the magnitude of current is reduced and vice versa. Therefore, the generated power for larger air gap is lower than that with smaller air gap. The generated powers for different air gaps are shown in Fig. 9.

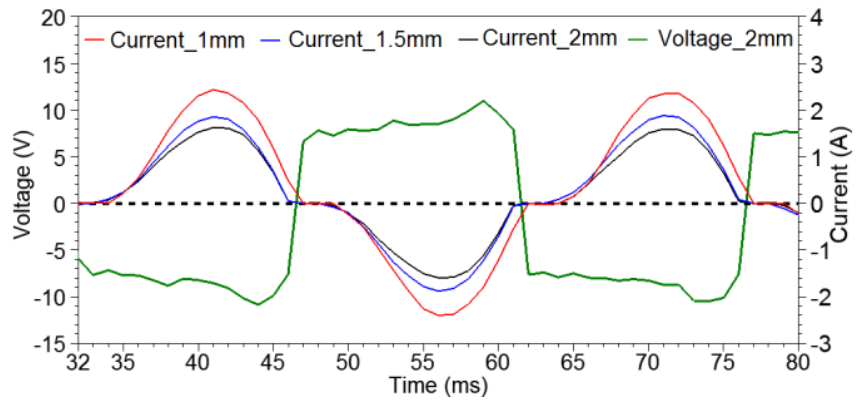

Fig. 8. Generated voltage and currents with different air gap lengths.

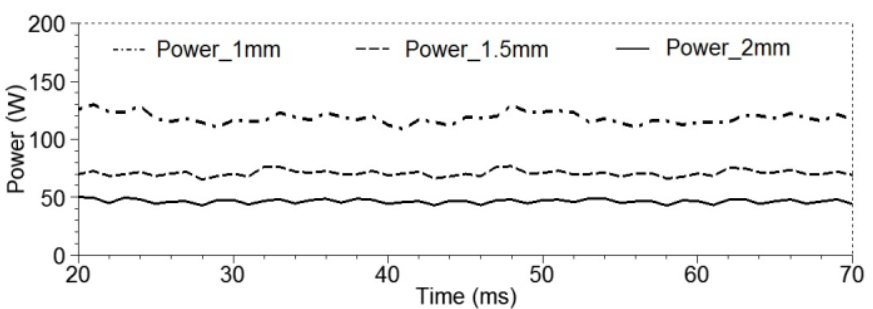

Fig. 9. Generated powers at different air gap lengths.

The amount of required applied force, Force_z depends on several factors. The Force_z applied to the translator for the 3 ohm load condition for different air gaps are shown in Fig. 10. The negative value of Force_z indicates that the force is applied to the translator, not generated. The flux linkage of winding 1 and 6 which are $180^{\circ}$ phase shifted each other and SM are shown in Fig. 11. This figure also show that the amount of flux linkage in winding 1 and 6 is higher for $1.5 \mathrm{~mm}$ air gap compare to the same for $2 \mathrm{~mm}$ air gap. The same parameter is also tested for $1 \mathrm{~mm}$ air gap and the value of flux linkage is found more. Therefore the coupling coefficient is higher for low air gap.

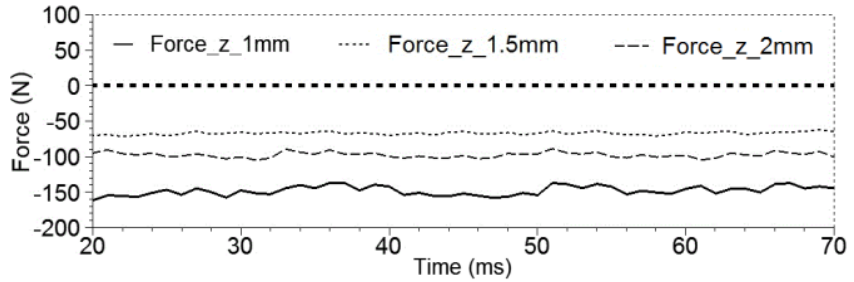

Fig. 10. Applied force with different air gap lengths.

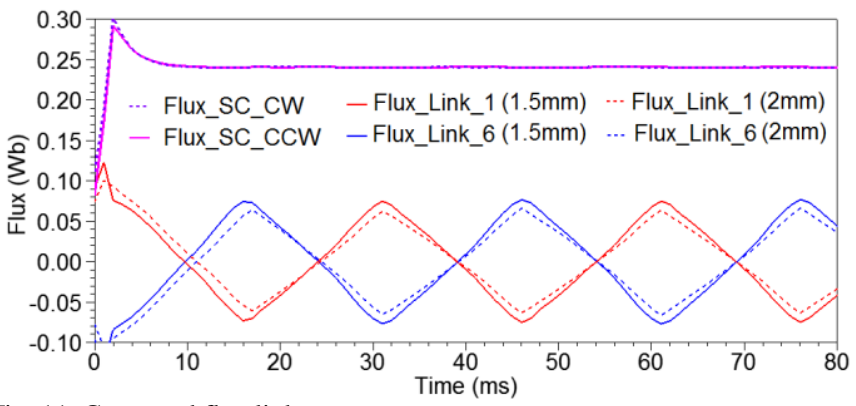

Fig. 11. Generated flux linkage.

The $B-H$ curve of the steel core that has been used in the proposed EMLG design simulated in this paper and the core loss data as a graph used in the simulation and known as $B-P$ curve for a specific frequency are given in Figs. 12(a) and 12(b), respectively. The frequency is measured as $50 \mathrm{~Hz}$ for 1.5 $\mathrm{m} / \mathrm{s}$ velocity of the $\mathrm{LG}$.

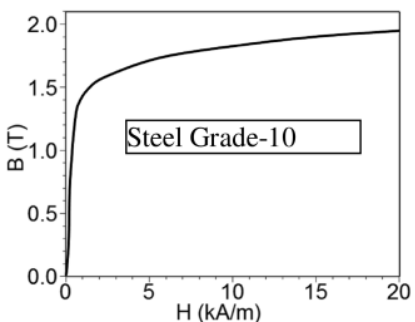

(a)

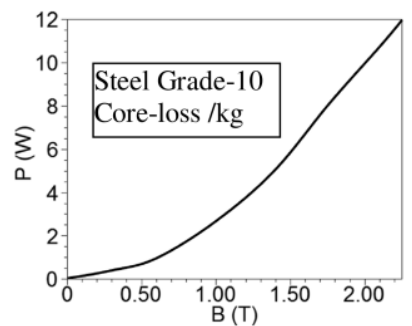

(b)
Fig. 12. (a) The B-H curve and (b) The core loss of the steel core.

The generated ac electrical power is rectified and the voltages and currents for different load conditions are shown in Fig. 13. It is seen that with the decrease in load the generated voltage is increased and the current is decreased. Therefore, there is a power variation and the maximum power is found at the $m_{l}$ point for the $2 \Omega$ load which is shown in Fig. 14. The power, efficiency and forces for different load conditions are also shown in this figure. The maximum efficiency is found in $m_{2}$ point which indicates $10 \Omega$ load and the maximum efficiency is found as $96.06 \%$ without considering frictional and other mechanical losses. The operating point indicates the default values.

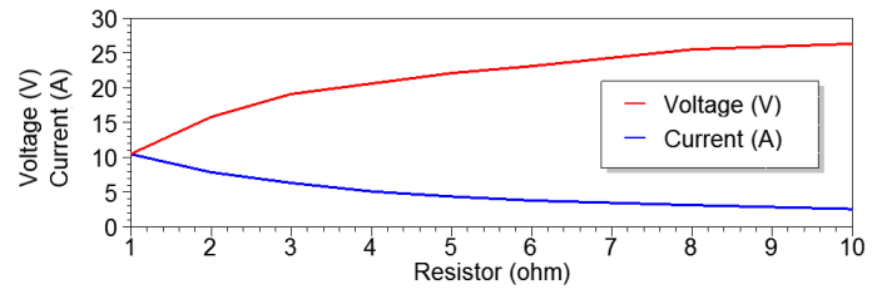

Fig. 13. Voltages and currents at different loads. 


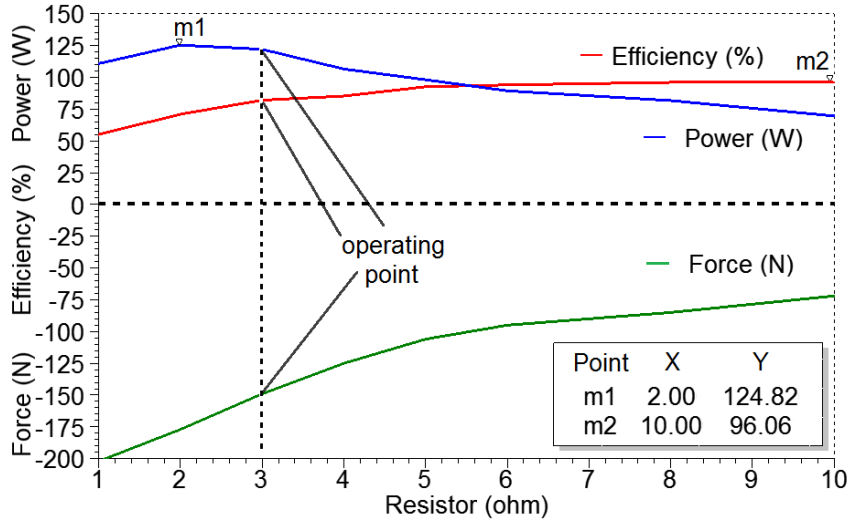

Fig. 14. Force, power and efficiency versus load.

Fig. 15 shows the mesh plots of the stator and translator core of the proposed LG and the isometric view of wounded stator.

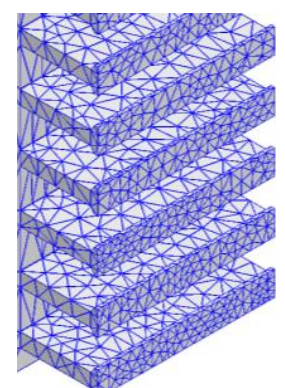

(a)

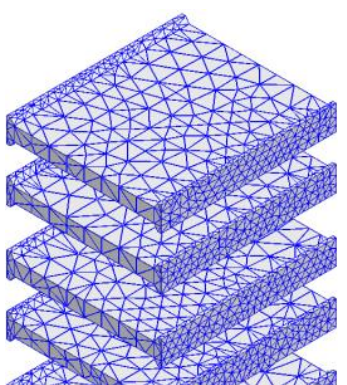

(b)

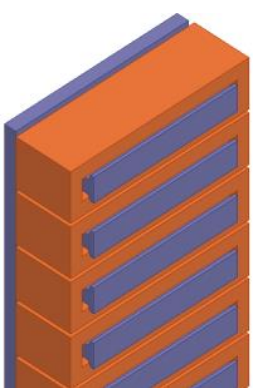

(c)
Fig. 15. Mesh plot of (a) Stator, (b) Translator core, and (c) wounded stator.

\section{CONCLUSION}

The proposed EMLG can generate electrical power effectively as the conventional PMLG, but it does not have the problem of demagnetization. In addition, from simulation results it is clear that the core loss is low which will avoid overheating. The cogging force and force ripples are low; this is helpful in reducing harmonic components and avoids abnormal operation of generator. It is also shown in the simulation that the output power of EMLG can be regulated by changing the field excitation, so it is possible to regulate output voltage and also power for different conditions of sea waves. The individual unit of the proposed EMLG offers all benefits and features of the proposed EMLG. The average core loss is $0.3 \mathrm{~W}$ when it generates $100 \mathrm{~W}$ electrical power. Therefore, core loss is only $0.3 \%$ and this low core loss is very significant to maintain cryogenic liquid temperature as the superconductor will lose its superconductivity above critical temperature. Therefore, magnet quenching problem will be minimized. In summary, the proposed design is suitable for superconducting materials. In addition, the proposed generator exhibits good performance in wide range of load variations and is capable of delivering more electrical power in overload condition.

\section{REFERENCES}

[1] M. R. Islam, Y. G. Guo, J. G. Zhu, H. Y. Lu, and J. X. Jin, "Highfrequency magnetic-link medium-voltage converter for superconducting generator-base high power density wind generation systems," IEEE Trans. Appl. Supercond., vol. 24, no. 5, art. 5202605, Oct. 2014.

[2] M. R. Islam, G. Lei, Y. G. Guo, and J. G. Zhu, "Optimal design of highfrequency magnetic-links for power converters used in grid connected renewable energy systems," IEEE Trans. Magn., vol. 50, no. 11, art. 2006204, Nov. 2014.

[3] R. Vermaak and M. J. Kamper, "Design aspects of a novel topology aircored permanent magnet linear generator for direct drive wave energy converters," IEEE Trans. Ind. Electron., vol. 59, no. 5, pp. 2104-2115, May 2012.

[4] J. Prudell, M. Stoddard, E. Amon, T. K. A. Brekken, and A. V.Jouanne, "A permanent-magnet tubular linear generator for ocean wave energy conversion," IEEE Trans. Ind. Appl., vol. 46, no. 6, pp. 2392-2400, Nov. -Dec. 2010.

[5] H. Zhang, Z. Nie, X. Xiao, R. Aggarwal, Q. Kang, M. Ainslie, J. Zhu, T. Coombs, and W. Yuan, "Design and simulation of SMES system using YBCO tapes for direct drive wave energy converters," IEEE Trans. Appl. Supercond., vol. 23, no. 3, art. 5700704, Jun. 2013.

[6] N. M. Kimoulakis, A. G. Kladas, and J. A. Tegopoulos, "Power generation optimization from sea waves by using a permanent magnet linear generator drive," IEEE Trans. Magn., vol. 44, no. 6, pp. 15301533, Jun. 2008.

[7] L. Huang, J. Liu, H. Yu, R. Qu, H. Chen, and H. Fang, "Winding configuration and performance investigations of a tubular superconducting flux-switching linear generator," IEEE Trans. Appl. Supercond., vol. 25, no. 3, pp. 1-5, Jun. 2015.

[8] L. Huang, H. Yu, M. Hu, J. Zhao, and Z. Cheng, "A novel fluxswitching permanent-magnet linear generator for wave energy extraction application," IEEE Trans. Magn., vol. 47, no. 5, pp. 1034-1037, May 2011.

[9] Y. G. Guo, J. X. Jin, J. G. Zhu, H. Y. Lu, "Design and analysis of a prototype linear motor driving system for HTS maglev transportation," IEEE Trans. Appl. Supercond., vol. 17, no. 2, pp. 2087-2090, Jun. 2007.

[10] J. X. Jin, L. H. Zheng, Y. G. Guo, J. G. Zhu, C. Grantham, C. C. Sorrell, and $\mathrm{W} . \mathrm{Xu}$, "High-temperature superconducting linear synchronous motors integrated with HTS magnetic levitation components," IEEE Trans. Appl. Supercond., vol. 22, no. 5, art 5202617, Oct. 2012.

[11] J. X. Jin, L. H. Zheng, Y. G. Guo, J. G. Zhu, "Performance characteristics of an HTS linear synchronous motor with HTS bulk magnet secondary," IEEE Trans. Appl. Supercond., vol. 47, no. 6, pp. 2469-2477, Nov.-Dec. 2011.

[12] Z. H. Wu and J. X. Jin, "Characteristic analysis of HTS linear synchronous generators designed with HTS bulks and tapes," IEEE Trans. Appl. Supercond., vol. 24, no. 5, pp. 1-5, Oct. 2014.

[13] F. G. R. Martins, D. H. N. Dias, A. C. Ferreira, R. Andrade, "Project of a HTS synchronous machine emulated by a linear motor," IEEE Trans. Appl. Supercond., vol. 25, no. 3, pp. 1-5, Jun. 2015

[14] I. Stamenkovic, N. Milivojevic, N. Schofield, and M. Krishnamurthy, "Design, analysis, and optimization of ironless stator permanent magnet machines," IEEE Trans. Power Electron., vol. 28, no. 5, pp. 2527-2538, May 2013.

[15] J. F. Pan, Y. Zou, N. Cheung, and G. Z. Cao, "On the voltage ripple reduction control of the linear switched reluctance generator for wave energy utilization," IEEE Trans. Power Electron., vol. 29, no. 10, pp. 5298-5307, Oct. 2014.

[16] R. K. Holm, N. I. Berg, M. Walkusch, P. O. Rasmussen, and R. H. Hansen, "Design of a magnetic lead screw for wave energy conversion," in Proc. 2012 XXth Int. Conf. on Electrical Machines, 2-5 Sept. 2012, pp. 618-626.

[17] M. A. F. M. Hamim, T. Ibrahim, and N. M. Nor, "Modeling and analyze a single-phase Halbach magnetized tubular linear permanent magnet generator for wave energy conversion," in Proc. 2014 IEEE Int. Conf. on Power and Energy (PECon), 1-3 Dec. 2014, pp. 87-92. 